\title{
Health Systems in an Interconnected World: A View from Nigeria
}

\author{
Seye Abimbola MD MPhil
}

\begin{abstract}
The benefits of an interconnected world for health care remain untapped. As a result of the politics of inequality between rich and poor countries, one or a few health systems are set up as models. Every country, irrespective of political or economic status, should be open to learning from others to build relevant and cost-effective systems. To combat the current global challenge of chronic noncommunicable diseases, poor countries have the advantage of flexible health systems that are veritable laboratories of health systems research. Not only can research conducted in these health systems help harness the potential of mobile communication technologies and informal health providers, it can also help rich country health systems adapt to meet the chronic disease challenge.
\end{abstract}

KEYWORDS Health care delivery, health care systems, access to health care, telemedicine, health manpower, chronic disease, Nigeria

\section{THE PERSISTING BLNDNESS OF SUPERIORITY}

The notion that one model for health care-the Western onecan serve us all now and in the future is the biggest obstacle to achieving a truly interconnected world and combatting the emerging global challenges of health and social wellbeing. We need to shed historical baggage and make way for a global network of unique health systems. The Nigerian health system with all its flaws ought to be able to speak to the flaws in the National Health Service in England, for example. We must create a global community of equality where innovation can flourish shorn of impositions and obsequious docility. Health systems research that is context-specific and sensitive is important for achieving this rich and diverse ecosystem. Panacea only exists in myths and fairy tales. There are more ways than one to skin a cat.

\section{THE NON-EXISTENT HEALTH SYSTEM}

Here is a thought experiment: imagine a country without a health system; the chaos, the inefficiency. The only form of health systems research one should conduct in a country without a health system is that which generates evidence to drive policy towards creating a system to achieve universal coverage. The research should not only be about which interventions work best, but within which settings the interventions that work best would be optimal. Indeed, most countries, including Nigeria, have some form of health system with stratified care, yet a series of institutions and facilities dispensing health care do not a system make.

When we expand our understanding of what constitutes a health system to include its functioning and mission, it becomes clear that the thought experiment is not quite so far-fetched: a health system consists of people, institutions and resources held together by ideals. These ideals include improving population health, protecting people from the cost of ill-health, providing health care with fair treatment to all, and responding to non-health expectations related to health; e.g., education. When considered in this light, Nigeria, like many other countries in the world, rich and poor, does not have a health system. No health system can en- tirely meet these ideals but they are worthy goals. However, in human history, this may be the first period when the absence of a health system in a country may have advantages.

\section{THE COMING REVOLUTION}

The world is at a watershed, on the brink of monumental change in its understanding of what constitutes health care and life in general. The revolution in communications with the internet and mobile connectivity; increasing aging in populations; increasing shift from acute and inpatient care to health systems predominantly grappling with chronic disease; and management of risk factors instead of disease states-all these are changing the way we perceive life and health.[1] Infectious disease was the paradigm for health care in the last century. For the 21st century, the paradigm will be self-management, risk factor management and chronic disease.[2] How to organize health care systems for these peculiar challenges is a research question that has received limited attention. The cost of caring for an aging population with lifelong chronic disease will run the governments of poor countries aground if we continue to rely on outdated, imported models, adopted unthinkingly.

The question then arises: how would one go about building a health system for the 21st century? This is where countries "without a health system" have the advantage. There is an opportunity to build afresh, with concepts and practice informed by research evidence in the light of these new realities. We must be proactive and innovative. In an informal survey of recent graduates of a Nigerian medical school, on what could be done to strengthen the Nigerian health system, suggestions were mostly about the need to strengthen primary care, address the problem of distributive justice and wrest the running of health care from doctors, who are mostly patronizing and parochial in their view of what constitutes health care and who often have had no training in management.

In addressing these issues, what first comes to mind is the cultural and social revolution sweeping through Nigeria with the advent of the mobile phone. Mobile phone use in Nigeria rose exponentially in rural and urban settings following its introduction in 1999, and penetration is presently estimated to be about $50 \%$ with about 80 million mobile phone subscriptions. Nigeria is the fastest growing mobile phone market in Africa and one of the fastest in the world with a quarterly increase of more than 7 million subscriptions.[3,4] In spite of its immense impact on economic and social life in Nigeria, the potential benefits of mobile phones in health care have not been sufficiently investigated. Mobile phones have been used around the world to support patients for medication adherence, appointment reminders, monitoring, self-management, reporting test results, and collecting data between appointments. Thus, one research challenge is to study how to fashion health systems based on remote consulting to achieve universal coverage.

\section{NEW CHALENGES, NEW PARADIGMS}

The chronic disease challenge There is an increasing prevalence of cardiovascular disease in sub-Saharan Africa, with many patients presenting only when their conditions become emergen- 


\section{Perspective}

cies, owing to poor access to health care due to cost, distance, and poor self-monitoring.[5] Presently, about $70 \%$ of the health budget in Nigeria goes to hospital and tertiary care,[6] which underperform because a few hospitals serve a huge population; their normally poor resources are often stretched thin due to overcrowding by outpatients with chronic disease and inpatients with fatal but avoidable emergencies. This expensive model with emphasis on tertiary centers has resulted in neglect of primary care and population-oriented preventive interventions, thereby denying a vast majority of Nigerians access to health care.

In order to better serve these patients, a study of the use of mobile phones for remote consultation for self-management and monitoring of diseases and symptoms (e.g. blood pressure and blood glucose level) is being conducted in Nigeria. It will explore the potential for cheaper alternative strategies for managing chronic disease risk factors by preventing emergency presentations, improving care for remote patients, and reducing patient load in institutional settings. The results of this study will inform our thinking on how to structure primary care in Nigeria to boost access to health care.

The UN General Assembly has agreed to hold a special session on chronic non-communicable diseases in September 2011, marking global recognition of the emerging health crisis. While strengthening health systems for access to treatment has been mentioned among priority actions proposed for discussion at the meeting, how to achieve this has received much less attention compared to other interventions such as tobacco control, salt reduction, improved diets and physical activity.[7] It is important that the meeting not ignore strategies required for the actual reorganization of health systems so that people can effectively access treatments for the control of chronic diseases.

The problem of distributive justice The hitherto great emphasis of the Nigerian health system on tertiary care also breeds a blinding obsession with state-of-the-art gadgets; for example, a government hospital runs a world class renal transplantation program, but does not have working suction machines in its pediatric emergency rooms. The suction machines would prevent many more deaths, but in a much poorer social stratum. This injustice in health resource distribution is reminiscent of the inverse care law noted by Julian Tudor-Hart which states that "the availability of good medical care tends to vary inversely with the need for it in the population served,"[8] warning that, "if those who shout loudest get heard first, we need to know when to train our ears to be deaf."[9] We must research the best ways of allocating health care to maximize the impact of limited funds with justice and equity.

The "friendly neighborhood pharmacy" The Nigerian newspaper, NEXT, recently published a feature entitled Your Friendly Neighbourhood Pharmacy. The author stated that "some of the pharmacies have served their neighbourhood long enough that they are now trusted sometimes more than hospitals" and "their proximity makes them the doctors next door."[10] However, the author had also unwittingly implied that attendants at the pharmacies prescribe drugs. This resulted in a comment on the newspaper's website, m234next.com:

"This is quite frankly a problem in Nigeria. Pharmacists are not supposed to prescribe, but dispense drugs. They are not trained in diagnosis of disease. I wonder why such an article can be published, quite openly stating that these chaps are contravening the law."
And another replied:

"The featured pharmacy is indeed the trusted neighbourhood pharmacy which l've known since my University days. Now I live...[27 km away], but when I can help it, I still prefer to get my drugs from [the] pharmacy. While the writer may have made a slip by indicating that pharmacists prescribe drugs, the purpose of publishing this article should not be lost."

This exchange illustrates the chasm between the pragmatic and the pedantic. What normally obtains is that doctors stay in hospitals, often remote and expensive, waiting for patients to come in and consult. The friendly neighborhood pharmacy is an existing and more trusted outreach facility, where trained health workers could be more accessible to people at no extra cost. Many children who die of malaria die because of delay in seeking treatment, usually lasting for about three days; when treatment is eventually sought, about two third of mothers do so outside the formal health sector, including from patent medicine vendors.[11]

The Nigerian landscape is dotted with failed primary health care centers built in the wake of the 1978 Alma Ata Declaration.[12] These projects failed largely because they were impositions on communities, contrary to the prescriptions of the Declaration. If people have structures and systems to which they have grown loyal and accustomed, we must opt to build health systems around them. It is imperative to carry out health systems research aimed at exploiting this interconnectedness at the individual level and adapting current trends in communication, information and health-seeking behavior to maximize access.

The health workforce The old system with doctors at the pinnacle overseeing all stages of health care no longer serves: it is way too expensive and probably unnecessary. Nigeria cannot afford to employ the doctors it invests heavily in training, an important reason for the efflux of Nigerian doctors to the West. These doctors are trained in high-tech teaching hospitals with the pomp and expectations that make them more comfortable in rich settings. Training doctors is expensive, so is employing them. In a world where the sophisticated skills of doctors will likely be in demand by fewer people, we must rethink and research how to distribute finite resources to the training and employment of a broader health workforce.

\section{INTERCONNECTED WORLDS BLIND TO ONE ANOTHER}

Nigel Crisp, former CEO of the National Health Service in England asked an important question:

"There is an unfair import-export business in people and ideas that flourishes between rich and poor countries. Rich countries import trained health workers and export their ideas and ideology about health to poorer ones, whether or not they are appropriate or useful. What, I ask, if we were to turn the world upside down-so the import-export business was reversed and poorer countries exported their ideas and experience whilst richer ones exported their health workers?"[13]

We must overcome this obstacle to achieving true interconnectedness and avoid reluctance to learn from other parts of the world owing to national pride and blind patriotism. The ongoing debate in the USA about not wanting their health system to look to "socialized" medicine in the UK for inspiration speaks volumes.[14] While it is true that the USA cannot possibly adopt the UK system 
and vice-versa, there are always lessons to be learned from the other side. In another example, the text of a presentation given to an international audience describing comparative weaknesses in health systems using Nigeria's as case study was sent to a group of Nigerian doctors. Responses to the presentation included this damning statement: "I am disappointed that you have painted Nigeria in such a bad light...with the ultimate intention of bringing out the flaws in the Nigerian health system...we do not have to magnify the problem but be patriotic...."

The author's response was that patriotism does not demand dishonesty and that the purpose of such a presentation is not to attract tourists. Modern realities are forcing erstwhile developed and developing countries into similar realities and we must, rich and poor, global North and South, learn humility, tolerance and openness to see one another clearly for the opportunities and lessons each can bring. It is an age of new thinking and ideas. We must open our eyes, avoid blindness born of superiority or inferiority complexes, and hope to fulfill the prayer Robert Burns wrote one Sunday, when spying a head louse on the bonnet of an upper-class lady reminded him that, to a louse, we are all equal prey:
"... and would some Power the small gift give us

To see ourselves as others see us!

It would from many a blunder free us, And foolish notion..."[15]

\section{CONCLUSION}

We need to investigate, adapt and assess features of our health systems as we plan for the 21st century, considering interconnectedness at the individual level with a focus on the benefits of the electronic age, telemedicine, potential for remotely-assisted diagnosis and self-management, the changing role of doctors, and global disease patterns. And we must tap into the benefits of an interconnected world at the level of nations, regions, and communities to learn from one another and absorb lessons critically in a global atmosphere of equality. The health challenges we face are global, but realities are local, and so must be the solutions. The poorer countries of the world will be the theater of research activity for building the 21 st century health system. For rich countries, ossified tradition is a major obstacle to research for change. We are challenged to see with new eyes, eyes of the future, to think as if we were indeed blessed with the task of building health systems from scratch. -1 -

\section{REFERENCES}

1. Bodenheimer $\mathrm{T}$, Lorig $\mathrm{K}$, Holman $\mathrm{H}$, Grumbach K. Patient Self-management of Chronic Disease in Primary Care. JAMA. 2002 November 20;288(19):2469-75.

2. Nabel E, Stevens S, Smith R. Combating chronic disease in developing countries. Lancet. 2009 Jun 13;373(9680):2004-6.

3. Nigeria mobile subscriber base hits 78.5 million. Telecompaper [Internet]. 2010 Apr 17 [cited 2011 May 23]; News:[about 1 p.]. Available from: http://www.telecompaper.com/news/nigeria-mo bile-subscriber-base-hits-785-million

4. Baez G, Kechiche B. The Impact of Mobile Services in Nigeria: How Mobile Technologies Are Transforming Economic and Social Activities. Pyramid Research. Abuja, Nigeria [Internet]. United Kingdom: Pyramid Research; 2010 Mar 16 [cited 2011 May 23]. 33 p. Available from: www.ictregulationtoolkit.org/en/ Document.3913.pdf

5. Bertrand E, Muna WF, Diouf SM, Ekra A, Kane A, Kingue $S$, et al. [Cardiovascular emergencies in sub-Saharan Africa]. Arch Mal Coeur Vaiss. 2006 Dec;99(12):1159-65. French.

6. Soyibo A, Olaniyan O, Lawanson AO. National Health Accounts of Nigeria, 2003-2005. Incorporating Sub-National Health Accounts of States. Volume 1: Main Report [Internet]. Abuja: Federal Ministry of Health (NG); 2009 Aug [cited 2011 May 23]. 174 p. Available from: http://www.who. int/nha/country/nga/nigeria_nha_2003-2005_ report.pdf

7. Beaglehole R, Bonita R, Horton R, Adams C, Alleyne $G$, Asaria $P$, et al. Priority actions for the non-communicable disease crisis. Lancet. 2011 Apr 23;377(9775):1438-47.

8. Hart JT. The inverse care law. Lancet. 1971 Feb 27:1(7696):405-12.

9. Longmore M, Wilkinson I, Rajagopalan S. Oxford Handbook of Clinical Medicine. $6^{\text {th }}$ ed. Oxford: Oxford University Press; 2004.

10. Okpi A. Your friendly neighbourhood pharmacy. NEXT [Internet]. 2010 Mar 20 [cited 2011 May 23]; News:[about 2 p.]. Available from: http://234next.com/csp/cms/sites/Next/News/ Metro/5543296-147/your_friendly_neighbour hood_pharmacy_.csp

11. Agu AP, Nwojiji JO. Childhood malaria: mothers' perception and treatment-seeking behaviour in a community in Ebonyi State, South East Nigeria. $\mathrm{J}$ Community Medicine and Primary Health Care. 2005;17(1):45-50.

12. WHO. Declaration at the International Conference on Primary Health Care, Alma-Ata [Internet]. Geneva, Switzerland: World Health Organization; 1978 [cited 2011 May 23]. Available from: http://www.who.int/hpr/NPH/docs/declaration_ almaata.pdf

13. Crisp N. Turning the World Upside Down: The Search for Global Health in the 21st Century.
London: Royal Society of Medicine Books; 2010. $228 \mathrm{p}$.

14. BMJ: British Medical Journal [Internet]. London: BMJ Publishing Group Limited; c2011. BMJ Blogs. Smith R. Is it unpatriotic to criticize the NHS?; 2009 Aug 17 [cited 2011 May 23]; [about 2 screens]. Available from: http://blogs.bmj.com/ bmj/2009/08/17/richard-smith-asks-is-it-unpatriotic-to-criticise-the-nhs/

15. Burns R. The Complete Poems and Songs of Robert Burns. Glasgow: Geddes \& Grosset Ltd; 2002. $480 p$

\section{THE AUTHOR}

Seye Abimbola (seyeabimbola@hotmail. com), physician with a master's degree in epidemiology. Research fellow at the $\mathrm{Na}$ tional Primary Health Care Development Agency, Abuja, Nigeria.

\section{Submitted: April 4, 2011}

Approved for publication: June 19, 2011

Disclosures: None 